\title{
Algumas Concepções de Direito e suas Lacunas ${ }^{1}$
}

\author{
Juan Ruiz Manero²
}

Resumo: $\mathrm{O}$ artigo inicia com uma análise das relações entre casos e normas jurídicas naquilo que se pode chamar "modelo clássico" de Alchourrón e Bulygin, correspondente à obra "Normative Systems", de ambos os autores. O autor assinala como as teses desse "modelo clássico" impedem a percepção quanto aos desacertos entre os juristas e como elas contrastam fortemente com as crenças compartilhadas entre eles; crenças essas que, a juízo do autor, são constitutivas da realidade do Direito. Problemas análogos apresenta a construção de Joseph Raz, outro grande expoente contemporâneo do positivismo chamado "forte" ou "excludente". Ambas as construções, de Alchurrón e Bulygin e a de Raz, têm em comum, na opinião do autor, uma visão empobrecida da variedade de normas regulativas. Na segunda parte, o autor trata de apresentar um modelo alternativo de abordagem das relações entre casos e normas a partir de uma visão da dimensão regulativa do Direito que apresente esta como sendo composta de dois níveis: o das regras e o dos seus princípios subjacentes. Finalmente, o autor apresenta algumas reconstruções coerentes com o modelo anterior, no que se refere aos conceitos de lacuna normativa e de lacuna axiológica.

Palavras-chave: Normas regulativas. Regras. Princípios. Lacunas. Lacunas normativas. Lacunas axiológicas.
Abstract: The article begins with an analysis about the relations between cases and juridical norms on what may be called "classic model" by Alchurrón and Bulygin, corresponding to the work "Normative Systems", by both authors. The author notes how how the thesis of this "classic model" prevent the perception on the mistakes between the jurists and how they strongly contrast with the shared beliefs between them; beliefs which, in the author's opinion, are constitutive of the reality of Law. Analogue problems presents the construction of Joseph Raz, another great contemporary exponent of the so-called "Strong" or "excludent" positivism. Both constructions, by Anchurrón and Bulygin and by Raz, have in common, in the author's opinion, and impoverished vision on the variety of regulative norms. On the second part, the author presents an alternative model of approaching the relations between cases and norms from a vision of the regulative dimension of Law which presents it as composed by two levels: the rules and the underlying principles. Finally, the author presents some coherent reconstructions to the previous model, in which refers to the concepts of normative gap and axiological gap.

Keywords: Regulative norms. Rules. Principles. Gaps. Normative gaps. Axiological gaps.

1 Tradução feita pelo professor Luiz Henrique Urquahrt Cademartori. Todas as citações diretas foram traduzidas livremente pelo professor Luiz Henrique Urquhart Cademartori. E-mail: luiz.hc@terra.com.br.

2 Professor catedrático de Filosofa do Direito da Universidade de Alicante. E-mail:juan.ruiz@ua.es 


\section{Introdução}

Em setembro de 2002, tive a oportunidade de ouvir - no seminário García Maynez de Teoria do Direito, realizado no México - DF - a palestra de Eugênio Bulygin, chamada "criação e aplicação do Direito". Nessa palestra - aqui reproduzida em versão ulterior - Eugênio Bulygin, a propósito da abordagem das lacunas, escolhia como representantes do "Eixo de erro", sobre o qual lançava seu ataque, não sei se preventivo, a Fernando Atria - a quem eu até então não conhecia e nem tinha lido - e a mim mesmo.

Pouco depois - em outubro do mesmo ano - tive a oportunidade de conhecer Fernando Atria e de ler pela primeira vez um trabalho seu Legalismo, direitos e política -, sobre o qual travamos uma longa e, por momentos, agitada discussão no Seminário do departamento de Alicante. O trabalho de Fernando Atria, por um lado, pareceu-me de grande qualidade, mas, por outro, eu me encontrava - e assim continuo - em profundo desacordo com os posicionamentos teóricos de Fernando a respeito do controle jurisdicional de constitucionalidade, sendo as posições relativas a esse tema que constituem as conclusões principais do trabalho dele. Naquela mesma ocasião, Fernando me deixou saber que estava preparando um livro de textos dele mesmo e de Eugenio Bulygin sobre o problema das lacunas normativas e me convidou a participar do projeto, ao qual, naturalmente, aceitei com satisfação, somando a ele alguma contribuição.

Tal como já tinha dito naquela época, eu não havia lido nenhum texto de Fernando Atria com exceção do trabalho, citado anteriormente, Legalismo, direitos e política. Considerando que tenho a tendência de formar impressões precipitadas - que, naturalmente, resultam equivocadas na maioria das vezes - ocorreu-me a ideia (partindo do nosso desacordo sobre judicial review) de que, sobre as lacunas, iria ficar em desacordo com Fernando tanto quanto estava com Eugenio Bulygin, cujas teses sobre o tema venho discutindo - com uma obstinação que apenas a boa 
vontade de Eugenio sabe desculpar - ao menos desde o livro de 1990, Jurisdição e Normas ${ }^{3}$.

A leitura dos textos de ambos os autores, aqui mencionados, permitiram-me, no entanto, perceber que, ao menos quanto a Atria, nossas ideias não se opunham tanto assim. Minhas posições a respeito dos temas aqui discutidos se encontram próximas às teses defendidas por ele, já que Eugenio Bulygin segue, de forma irredutível, fiel a uma concepção de Direito e de racionalismo jurídico da qual discordo profundamente. Minha contribuição, pois, a essa discussão consistirá em expor novamente, a partir de um enfoque ao menos parcialmente novo, minhas discordâncias com Eugenio Bulygin. Para isso, procederei da seguinte forma: irei expor em primeiro lugar como se articulam as relações entre casos e regras (e a hipótese das lacunas) de acordo com o que podemos chamar de modelo clássico $^{4}$ de Alchourròn e Bulygin, fazendo também uma breve referência ao enfoque de Raz. Posteriormente, esboçarei uma visão alternativa dos mesmos problemas e concluirei com algumas reformulações dos conceitos de Lacuna Normativa e de Lacuna Axiológica, que me parecem mais adequadas para a realidade dos nossos sistemas jurídicos do que os conceitos originais que encontramos em Normative Systems.

\section{Sobre as Relações entre Casos e Regras nas Concepções de Direito de Alchourrón, Bulygin e Raz}

O que está na base do tratamento que dá Alchourrón e Bulygin ao problema das lacunas é uma concepção da dimensão reguladora do direito

\footnotetext{
3 Na obra, discute-se a distinção entre permissões fortes e fracas e sua relevância para o problema das lacunas, em Ruiz Manero, Jurisdicción y normas: 37 ss.; em Atienza y Ruiz Manero, Las piezas del derecho. Teoría de los enunciados jurídicos: 100 ss.; em Ruiz Manero, Algunos límites de la teoría del derecho de Alchurrón y Bulygin": 115 ss.

4 Entendo por modelo clássico aquele contido em Normative Systems e nos trabalhos, em conjunto ou em separado, de ambos os autores que resultam consistentes com essa obra. Parece-me plausível supor que os últimos trabalhos de Alchourròn sobre as condicionantes derrotáveis pudessem terminar por implicar uma revisão profunda de tal modelo, mas essa questão não será abordada aqui. Em todo caso, nos textos aqui reproduzidos E. Bulygin permanece estritamente fiel ao que chamo de modelo clássico.
} 
que vê a este, exclusivamente, como um conjunto de unidades - as diversas regras jurídicas - que correlaciona cada uma dessas unidades (outros tantos casos genéricos) com alguma solução normativa. Essas unidades ou regras podem ser ou o produto direto de uma fonte ou, então, fruto das consequências lógicas das unidades que são produto dessa fonte. De tal modo que, enfrentando um caso individual, a tarefa do jurista se limita a comprovar se o conjunto de propriedades que tal caso individual apresenta resulta ou não subsumível ao conjunto de propriedades que constituem o caso genérico correlacionado, em algumas dessas unidades ou regras, com alguma solução normativa. É possível que seja duvidoso - ou controvertido - se as propriedades que o caso individual apresenta são ou não subsumíveis às do caso genérico, isto é, se é possível que nos enfrentemos com o que os próprios autores, Alchourrón e Bulygin, chamam de lacuna de reconhecimento, ao que logo faremos alusão. De qualquer modo, só há duas possibilidades de resposta: o caso individual resulta subsumível; ou não resulta subsumível, no caso genérico. Na primeira suposição, quando se afirma a subsumibilidade, o caso individual tem uma solução jurídica predeterminada, isto é, a solução prevista na regra que contempla o caso genérico correspondente. Na segunda suposição, quando se nega a subsumibilidade, abrem-se duas possibilidades. A primeira é que o caso individual apresente propriedades que (ainda não constituindo um conjunto que resulte subsumível no conjunto de propriedades que configuram um caso genérico e uma regra do sistema) resultam pertencentes ao Universo de Propriedades consideradas como relevantes pelo sistema jurídico. Se as coisas são assim, o caso, visto como caso genérico (isto é, como um conjunto de propriedades) constitui uma lacuna normativa do sistema. A segunda possibilidade é que o caso apresente propriedades pertencentes ao Universo de Propriedades do Sistema e, sendo assim, o caso resulta juridicamente irrelevante, isto é, encontra-se além das fronteiras do Direito.

Deixando, então, de lado, os casos juridicamente irrelevantes, o que nos resta é que todos os casos que apresentam alguma propriedade pertencente ao Universo de Propriedades do sistema jurídico e a respeito dos quais as regras jurídicas guardam silêncio, isto é, todos os casos não irrelevantes em relação com os quais uma regra jurídica não correlaciona uma solução normativa, esses são os casos de lacuna normativa. Em tais 
casos, o que deve fazer o juiz? Frente a tais supostos de lacuna, os autores afirmam:

O juiz não tem nenhuma obrigação especifica, nem de condenar nem de impugnar a demanda. Só tem a obrigação genérica de julgar, e cumpre com sua tarefa julgando de qualquer das maneiras possíveis: condenando ou não. Em outras palavras: o juiz tem a obrigação de julgar, isto é, de condenar ou rechaçar a demanda, mas não deve condenar, como também não tem a obrigação de rechaçar a demanda [...] (ALCHOURRÓN; BULYGIN, 1971, p. 215).

Casos, pois, em que o juiz somente pode cumprir seu dever de resolvê-los ao preço de não cumprir com seu dever acerca de que tal solução se fundamenta no direito preexistente pela mera razão de que - de acordo com a concepção de Alchourrón e Bulygin - simplesmente não há tal direito preexistente: o juiz não pode resolvê-los criando uma norma que qualifique normativamente, para o caso genérico correspondente, a ação em questão, e fundamente em tal norma a solução do caso individual. $\mathrm{O}$ fato de que tal norma geral criada pelo juiz possibilita fundamentar ou a admissão ou a denegação da demanda poderá ser mais ou menos razoável ou mais ou menos disparatada, mas estes juízos de razoabilidade ou de irrazoabilidade serão sempre puras apreciações extrajurídicas. Juridicamente, a decisão do juiz é inteiramente discricionária, no sentido de que não está vinculada a pautas jurídicas preexistentes, pois não há mais pautas jurídicas do que as que correlacionam casos com soluções e isto é, precisamente, o que falta aqui. Juridicamente, a decisão do juiz se encontra justificada sempre que se fundamenta numa regra geral construída pelo próprio juiz, e será igualmente justificada se de tal regra geral se deriva a admissão como se dela mesma se deriva a denegação da demanda. Eugenio Bulygin tem permanecido até o presente momento irredutivelmente fiel a essa reconstrução, como mostra sua aceitação do exemplo proposto por Fernando Atria a respeito do lugar de férias conjugais. $\mathrm{Na}$ opinião de Bulygin, se falta uma regra a respeito das obrigações (ou a ausência de obrigações) de um e de outro cônjuge, a decisão do juiz está justificada, sempre que se encontre mediada por uma regra geral criada por ele mesmo, da qual se derive, ou (no caso de que o juiz crie uma 
norma digamos "patriarcal") a obrigação da mulher seguir o marido ao lugar das férias escolhido por ele, ou (no caso do juiz criar uma norma digamos "matriarcal", ou se, preferir "feminista") a obrigação do marido de seguir a mulher ao local de férias escolhido por ela; ou, ainda, (no caso do juiz criar uma norma digamos "anarquista") a permissão para ambos de se omitirem das pretensões do outro. O juiz cumpre com a sua obrigação em qualquer das três suposições; em qualquer uma das três trata-se de uma decisão justificada e aqui tudo se resolve de forma satisfatória. De acordo com o direito, não há mais o que discutir.

Pode, evidentemente, ocorrer o caso em que duas regras jurídicas correlacionem o mesmo caso com soluções normativas incompatíveis, isto é, que o sistema contenha uma antinomia. Essa possibilidade, na opinião de Alchourrón e Bulygin, não se pode nunca excluir porque a consistência do sistema não é um traço garantido nele, mas meramente um ideal racional. Em todo caso, os sistemas jurídicos usualmente contêm meta-regras (constituídas por critérios de lex superior, lex posterior e lex specialis), que, ao hierarquizar as regras em conflito, possibilitam solucionar, mediante pautas proporcionadas pelo próprio direito, a maior parte das antinomias. Mas o que interessa destacar é que a consistência como traço que o direito apresenta, ou bem de entrada, pela ausência no seu seio, de regras inconsistentes, ou pela eliminação das inconsistências mediante meta-regras jurídicas - é um ideal racional de difícil realização plena, pela mera razão de nossa incapacidade para antecipar, mediante a configuração dos correspondentes casos genéricos, todas as combinações de propriedades que podem apresentar os casos individuais. Daí que, em relação com as normas que, como tais, são inconsistentes, podem aparecer supostos de inconsistência por certas combinações não previstas de fato (ou, se preferir, de propriedades, conforme Alchourrón). Um exemplo imaginário seria o seguinte: suponhamos uma norma $\mathrm{N} 1$, contida numa lei processual, de acordo com a qual todos os funcionários públicos teriam a obrigação de entregar ao juiz penal qualquer documento solicitado por este e, suponhamos também, uma norma N2, na qual todos os funcionários públicos ficam proibidos de entregar a quem quer que seja os documentos qualificados como secretos dos que tiverem conhecimento em razão do seu cargo. Quando tal situação ocorre com respeito a normas 
do mesmo grau (isto é, quando duas normas do mesmo grau aparecem como antinômicas no que se refere a combinações de propriedades não previstas pela autoridade editora de ambas), o direito teria critérios para sua solução: porque o critério de lex posterior resulta aqui irrelevante e de lex specialis pode funcionar em ambos os sentidos (tanto pode entender-se que "juiz penal" é especial frente a "quem quer que seja" como que "documento classificado como secreto" é especial frente a "qualquer documento") pelo que não se chega a uma solução. O juiz não teria outra possibilidade, ante a ausência de guias jurídicos para resolver a antinomia, senão escolher a forma não guiada pelo direito ("usando - diriam Alchourrón e Bulygin - seus critérios de preferência pessoal") entre uma e outra norma as quais resultam conflituosas para o caso. Sua decisão se acharia igualmente justificada tanto se escolhesse uma como se escolhesse a outra das normas em conflito.

Pode ocorrer também que, por razões de indeterminação semântica na descrição de alguma propriedade configuradora do caso genérico solucionado numa regra, resulte duvidoso - no sentido de que não haja usos linguísticos seguros a respeito - se uma propriedade (menos genérica) que exibe certo caso individual está ou não compreendida naquela. Um exemplo proveniente de Dworkin, do qual Alchourrón e Bulygin fazem uso, é a norma segundo a qual os contratos sacrílegos são nulos e, sendo assim, coloca-se a questão que, se o contrato entre Tim e Tom, celebrado no domingo é, por essa circunstância, sacrílego é, por essa razão, também nulo. O juiz deve estabelecer, pois, se os contratos celebrados no domingo estão incluídos ou excluídos da extensão "sacrílego". Nesse caso, por não haver uma regra linguística clara, o juiz deve usar, para fundamentar sua decisão, não uma definição lexicográfica ou informativa de "sacrílego", mas uma definição estipulativa (baseada numa decisão discricionária de sua parte). Essa definição estipulativa é, como seria no caso de se encontrar disponível a correspondente definição lexicográfica, uma proposição analítica que, como tal, "é verdadeira apenas em virtude do significado dos termos relevantes" e isto, naturalmente, desde que se estabeleça a inclusão na denotação de "sacrílego" dos contratos celebrados no domingo, tanto como se opta por excluir tais contratos de tal denotação. 
Sua decisão se encontra, de acordo com Alchourrón e Bulygin, igualmente justificada em ambos os casos.

Outro suposto caso que os juristas tendem a ver como problemático, mas que para Alchourrón e Bulygin resulta nítido, dá-se quando o sistema apresenta, em relação a certo caso (genérico), o que eles denominam de lacuna axiológica. De acordo com os autores esse caso constitui uma lacuna axiológica de um determinado sistema normativo se o caso em questão está solucionado por esse sistema normativo, mas sem que se considere como relevante para essa solução, certa propriedade que, de acordo com alguma hipótese de relevância, deveria ser considerada como relevante. Em tais situações, o caso está devidamente solucionado por esse sistema. O que ocorre nelas é que a solução é julgada como valorativamente insatisfatória por certo intérprete e/ou aplicador, os quais entendem que o legislador, de maneira axiológica inadequada, não considerou como relevante uma propriedade que, de acordo com a hipótese de relevância assumida pelo intérprete ou pelo aplicador, deveria ter sido tomada como relevante. Um bom exemplo de lacuna axiológica estaria constituído pelo famoso caso "Riggs versus Palmer", que Dworkin popularizou há mais de três décadas e que foi rebatizado por Carrio como El caso Del nieto apurado, vale dizer, "O caso do neto apressado". Como se lembrará, trata-se de um caso em que um neto reclamava, ao entrar em posse da herança de seu avô, que de acordo com as regras sobre a sucessão aplicáveis ao caso lhe corresponderia, sem dúvida alguma, a herança, porque tais regras não consideravam como relevante a propriedade, presente neste caso, de que quem reclama a herança tivera assassinado o avô. Pois bem, se reconstruirmos a situação de acordo com as categorias de Alchourrón e Bulygin, o que havia aqui era uma divergência valorativa entre a tese de relevância do sistema jurídico, as propriedades consideradas como relevantes nas regras do sistema para configurar os casos, para as quais a propriedade "ter assassinado o de cujus" aparecia como irrelevante, e uma hipótese de relevância externa ao sistema (a de que os juízes que assumiram este caso), para quem a propriedade "haver assassinado o de cujus" deveria ser considerada como relevante. Mas tal coisa é um mero desacordo valorativo que, como tal, não afeta a solução juridicamente predeterminada do caso, que não é mais que o que se deriva da regra que configura o caso e 
é produto das decisões sobre relevância do legislador e não das hipóteses, ou preferências, sobre relevância externas ao sistema de regras jurídicas.

Pois bem, se tudo o que anteriormente foi dito é correto (isto é, se é uma reconstrução adequada da tese de Alchourrón e Bulygin), encontramos-nos com uma primeira consequência geral sumamente chocante, qual seja, a de que, de acordo com a concepção de Alchourrón e Bulygin, não há espaço para falar da existência, no Direito, de casos a respeito dos quais seja controvertida a solução exigida pelo Direito: há casos que encontram sua solução numa regra preexistente e casos para cuja solução o juiz deve construir discricionariamente (ou escolher) a regra na qual deve subsumir tal caso. E "discricionariamente" deve entender-se aqui no seu sentido mais forte: como algo não guiado por normas jurídicas de nenhuma classe, de forma que qualquer discussão sobre a maneira como o juiz deve exercer a discricionariedade é uma discussão sobre preferências, alheias todas elas ao que, de acordo com o Direito, deve fazer-se. Mais especificamente, a relação entre casos individuais e regras pode apresentar, de acordo com o que é chamado "modelo clássico" de Alchurrón e Bulygin, as seguintes modalidades:

a) Casos claramente abrangidos por uma regra e só por uma regra (ou por duas ou mais regras redundantes): a solução jurídica correta é a predeterminada pela regra que configura o caso genérico correspondente, sem mais especificações. No particular, quando se alega que o caso individual apresenta propriedades que deveriam ser consideradas como relevantes e que não se encontram reconhecidas como tais na configuração do caso genérico (lacunas axiológicas), tais alegações não são nada mais que uma expressão de um desacordo valorativo externo ao direito.

b) Casos não abrangidos por regra alguma (lacunas normativas): é uma solução juridicamente correta qualquer decisão do juiz, desde que se fundamente numa regra geral.

c) Casos abrangidos por duas regras incompatíveis (antinomias) no que cabe resolver a incompatibilidade através das meta-regras de lex superior, lex posterior ou lex specialis: é uma solução juridi- 
camente correta fundada em qualquer das regras incompatíveis, entre as quais o juiz escolhe discricionariamente.

d) Casos duvidosos que resultam ou não passíveis de subsunção numa regra, por falta de determinação semântica dos termos empregados na configuração do caso genérico contemplado na regra (lacunas de reconhecimento). É correta a solução fundamentada em qualquer das interpretações possíveis dos termos empregados na configuração do caso genérico (tanto a que inclui o caso individual como a que exclui), entre as quais decide o juiz discricionariamente.

Parece que tudo isso apresenta uma imagem da relação entre casos e regras que resulta por completo alheia às ideias compartilhadas entre os juristas.

a) A respeito dos casos do tipo 1: os juristas devem considerar que as regras estão sujeitas a exceções implícitas que não resultam inteiramente antecipáveis. De forma que, quando eles mesmos se afastam da solução predeterminada por uma regra, entendem que fazem tal coisa por razões jurídicas e que também em tais casos aplicam o Direito e não o modificam com base nas suas preferências pessoais.

b) No que se refere aos casos de tipo 2:, parece que qualquer jurista consideraria que, se não há regras para certo caso, a conduta correspondente resulta, desse modo, de forma imediata, não vinculada juridicamente e, por isso, livre. Que resulte, de imediato, juridicamente não vinculada não quer dizer, entretanto, que resultem assim considerados todos os fatores. $\mathrm{O}$ direito pode conter elementos - que vão se explicitar de outra forma de racionalização análoga - que determinem que a conduta em questão deva considerar-se, nesse caso, como finalmente proibida pelo Direito. Em todo caso, a discussão a respeito de se a conduta em questão deve, no caso em que se trate, considerar-se finalmente como não vinculada juridicamente ou como proibida, é uma discussão a respeito do que o Direito, considerados todos os fatores, determina para o caso e não como uma discussão de preferências 
pessoais relativas ao uso de poderes de exercício não guiadas juridicamente.

c) No que se refere aos casos do tipo 3: isto é, antinomias não resolúveis pelo uso das meta-regras lex superior, lex posterior ou lex specialis, não parece que os juristas considerem que o juiz pode escolher uma das duas regras em conflito, senão que deverá atender ao peso, em relação com o caso, das razões subjacentes a uma e outra regra em conflito. E que os desacordos a esse respeito são desacordos a respeito da devida relação jurídica com o caso, e não, mais uma vez, desacordos relativos a preferências pessoais a respeito do uso de poderes de exercício não guiado juridicamente.

d) E, por último, os casos de tipo 4: dúvidas acerca da subsumibilidade de certa propriedade que exibe um caso individual na propriedade presente na configuração de um caso genérico, vale a pena voltar ao próprio exemplo com que operam Alchourrón e Bulygin - a subsumibilidade ou não da propriedade descritiva "celebrado no domingo" na propriedade valorativa "sacrílego". Confesso minha incompetência valorativa para emitir opiniões acerca do que deva ou não considerar-se "sacrílego", mas o que me interessa destacar é que o problema é similar ao que o legislador usa, para configurar o caso genérico, um termo que designa um conceito vago do tipo dos que os juristas gostam de denominar "conceitos jurídicos indeterminados". Quando o legislador usa, para guiar a conduta (para configurar o caso ou para caracterizar a ação) um "conceito jurídico indeterminado" - tal como "abuso de direito", "fraude de lei", "prodigalidade", "boa fé" etc. - o que faz é configurar o caso, ou caracterizar a ação, mediante propriedades valorativas, sem determinar que propriedades descritivas constituem as condições de aplicação da propriedade valorativa correspondente, conforme Richard Hare (1952). A tarefa de determinação dessas condições de aplicação é encomendada pelo legislador ao aplicador do Direito. O que não quer dizer, ao juízo dos juristas, que o órgão aplicador é habilitado para determinar, de qualquer maneira que lhe pareça apropriada, 
tais condições de aplicação. Um exemplo, os juristas não consideram que o órgão aplicador goze de discricionariedade para qualificar como "abuso de direito" qualquer caso de exercício de um direito subjetivo com o qual não simpatize. Também aqui os juristas consideram que há determinações das condições de aplicação corretas e incorretas. E, mais uma vez, as discussões sobre a correção ou a incorreção são, também nesse âmbito, discussões acerca do que o Direito exige num determinado uso de poderes de exercício não guiado juridicamente.

A apresentação que fazem Alchourrón e Bulygin da relação entre as regras e casos resulta, assim, não muito distante, mas fortemente contrastante com as crenças compartilhadas entre os juristas, os modos de argumentação que estes consideram aceitáveis e as pretensões que eles exprimem quando desenvolvem algum desses modelos de argumentação. De onde Alchourrón e Bulygin observam uma mera separação do exigido pelo Direito - na adoção de uma solução distinta da determinada numa regra aplicável ao caso pela presença de uma lacuna axiológica - os juristas entendem que esse afastamento pode estar juridicamente justificado, isto é, vem exigido pelo próprio direito, porque essa propriedade que a regra aplicável ao caso toma como relevante poderia ser que devesse, de acordo com o Direito e não com as hipóteses pessoais de relevância, ser tomada em conta como relevante. E assim mesmo, em aspectos nos quais Alchourrón e Bulygin observam pura discricionariedade - no sentido de faculdade para construir, selecionar ou precisar a norma que fundamenta a decisão em meras preferências pessoais - os juristas observam operações juridicamente vinculadas e apresentam suas opiniões a respeito como que pretendendo refletir o que o Direito exige para o caso. Os desacordos aparecem, assim, como verdadeiros desacordos jurídicos, e não como meros contrastes de preferências pessoais.

Suponho que Eugenio Bulygin poderia me conceder razão a tudo anteriormente dito e replicar que tudo isso, no final das contas, não tem a menor importância. Poderia arguir que a imagem que ele próprio e Carlos Alchourrón apresentam da relação entre casos e regras não se compadece com a imagem que, dessa mesma relação, tem os juristas, mas, sendo as- 
sim as coisas, pior para os juristas. Também não, por exemplo, - arguiria Bulygin - a teoria da evolução se compadece bem com a imagem do Gênesis e não implica problema algum para a primeira, salvo para o fanático religioso. Mas acontece que a história da evolução das espécies e essa instituição social que chamamos de "Direito" se encontram em níveis ontológicos distintos. E isso pela simples razão de que a evolução das espécies está constituída por fatos independentes de qualquer crença a respeito, enquanto que a existência e o modo de operar do Direito, são fatos dependentes de crenças compartilhadas. E, por esse motivo, qualquer Teoria do Direito que pretenda ser epistêmicamente objetiva, há de ser correspondente com as crenças (subjetivas, obviamente) compartilhadas pelos participantes na instituição, ou na prática social, a que chamamos "Direito".

De forma que, como veremos, não pode considerar-se casual esta mesma discordância com as crenças compartilhadas pelos juristas - e em particular, ao considerar como casos não regulados pelo Direito, casos que qualquer jurista consideraria como claramente regulados por ele -, isso também ocorre na obra de outro dos campeões contemporâneos do positivismo "forte", isto é, na obra de Joseph Raz.

Joseph Raz é, provavelmente, o defensor mais conhecido da concepção de Direito que se chama "positivismo excludente" ou "tese forte das fontes sociais". Tese a que Eugenio Bulygin (1981, p. 430 e ss.) considera "definidora da posição positivista". De acordo com ela, "a identificação de uma norma como norma jurídica consiste em atribuí-la a uma pessoa ou a uma instituição relevante (isto é, a uma fonte), como expressão de sua decisão e expressão de seu juízo" e "tais atribuições podem basear-se unicamente em considerações de fato", pois a argumentação moral "pode estabelecer o que é que as instituições jurídicas deveriam ter expressado ou sustentado, mas não o que realmente expressaram ou sustentaram", defende J. Raz (2001, p. 196).

Para compreender o alcance da tese de Raz, nada melhor do que um exemplo dado por ele mesmo. Podemos supor que uma norma ${ }^{5} \mathrm{~N} 1$

5 Raz, a rigor não fala em exemplo de norma, mas de doutrina jurídica. Mas uma doutrina jurídica, na terminologia da commom law, não pertence à linguagem acerca do Direito, mas à linguagem mesma do Direito. Essa é a razão do porquê da substituição na 
que estipule que "um contrato que propicia a corrupção na vida pública é ilícito" e uma decisão judicial D como a seguinte, que se apresenta como aplicadora da norma anterior: "considera-se ilegal um contrato pelo qual o contratante empreiteiro deveria contribuir com fundos para a campanha eleitoral de um candidato nas eleições locais, como retribuição pelo compromisso de que, no caso de resultar eleito, o candidato promoverá a construção de uma rua que interligue dois complexos habitacionais". Raz "dá por certo" que essa decisão "embora se encontre preparada para a linguagem específica que se refere ao caso particular, baseia-se numa preposição geral que se aplica a uma classe de casos" isto é, numa norma cujo teor viria a ser algo assim como N2 "se consideram ilegais aqueles contratos em que alguém proporciona fundos eleitorais a um candidato em troca do compromisso de que, uma vez eleito, tome alguma decisão específica". Suponhamos assim mesmo que N2, uma vez usada como ratio decidendi de $\mathrm{D}$, estabelece um precedente obrigatório, de forma que, a partir de D, N2 é indubitavelmente uma norma válida do sistema jurídico, expressamente formulada. Pois bem, antes da sentença, pertencia ao sistema jurídico uma norma, se bem que implícita, que estabelecia o que estabelece a norma N2? A resposta de Raz é negativa: pelo seu juízo, o tribunal, em tal caso, não se limitou explicitar o conteúdo do Direito já existente, mas modificou o Direito. Alguém poderia pensar que, efetivamente, assim são as coisas pela razão de que N1 não determina a decisão $\mathrm{D}$, mas que, de acordo com N1 era possível alguma decisão, por exemplo, a que se fundamentara na consideração de que a troca de dinheiro por promessas eleitorais não constituem uma forma de corrupção política e que, portanto, um contrato desse teor deve ser lícito. Não é essa a posição de Raz: este assume a posição de que: de acordo com N1 não cabia outra decisão senão a fundada em N2. Isso implica que o tribunal em questão deveria usar N2 como fundamento de decisão. E se assim é, que sentido tem a afirmação de que N2 não era uma norma válida do sistema anterior à decisão judicial? Que sentido tem, dizer que uma norma é uma norma jurídica válida, mas que os tribunais têm o dever de usá-la, nos casos apropriados, como fundamento de suas decisões? E se os deveres judi-

exposição do exemplo, da expressão doutrina jurídica pela expressão "norma", para não dar lugar a equívocos a respeito. 
ciais a respeito não são modificados, que sentido tem dizer que o direito mudou?

A resposta de Raz se encontra em uma concepção acerca das condições de verdade dos enunciados que afirma a existência das normas jurídicas válidas: um enunciado que afirma a existência de uma norma jurídica válida é verdadeiro, na opinião de Raz, apenas se sua verdade pode apoiar-se exclusivamente em premissas fáticas verdadeiras, sem recorrer a argumentos . Pois bem: "antes da sentença que estabeleceu a ilegalidade de tais contratos, não havia maneira de argumentar que existia uma norma legal que taxava a tais contratos de ilícitos, a menos que se buscasse apoio em argumentos morais; por isso, não existia direito algum a respeito" (RAZ, 2001, p. 200).

Logo, por que sustentar uma tese sobre as condições de verdade dos enunciados acerca da existência de normas? Como é sabido, isso depende, a partir do afirmado por Raz, da concepção acerca do Direito. Concepção que o vê como um mecanismo destinado a prescindir da deliberação na nossa determinação sobre os cursos de ação a adotar. As autoridades jurídicas deliberam sobre as razões pró e contra um determinado curso de ação, dadas certas circunstâncias. Sua deliberação produz certas instruções (ou "razões executivas") para os submetidos a elas (as normas jurídicas) que podem ser entendidas e seguidas sem ter que reabrir o processo deliberativo. Essa é a principal vantagem de dispor de autoridades jurídicas e de um sistema jurídico: seus destinatários podem economizar os custos de deliberação. Tal vantagem, como é óbvio, perder-se-ia para se estabelecer o significado das instruções das autoridades, atendendo às razões que elas mesmas têm levado em conta.

Pois bem, o problema é que as "instruções" das autoridades jurídicas nem sempre reúnem as condições necessárias para que seus destinatários possam poupar-se da deliberação. Essas condições reúnem-se quando as instruções da autoridade têm a forma de regras que correlacionam um caso genérico, configurado mediante uma combinação de propriedades descritivas, com a obrigação, a proibição ou a permissão de uma ação, caracterizada assim descritivamente. As normas desse tipo, por exemplo, “circulando por autoestrada, está proibido ultrapassar a velocidade de 120 
$\mathrm{km} / \mathrm{h}$ " - têm o que se chama autonomia semântica, isto é, seu significado pode estabelecer-se - e, portanto podem ser seguidas - sem atender às razões subjacentes nelas, as razões que as justificam. Mas o que ocorre quando as instruções sob a forma de regras - isto é, de enunciado que correlacionam um caso com uma solução normativa - configuram o caso mediante propriedades carentes de autonomia semântica a respeito das razões subjacentes à regra: por exemplo, o Código Civil espanhol determina que o juiz, dado o correspondente processo, declare incapazes - isto é, prive da capacidade de trabalhar - aquelas pessoas que apresentem "enfermidades ou deficiências permanentes de caráter físico ou psíquico que impeçam a pessoa de governar a si mesma". Aqui, seguir a regra sem atender suas razões subjacentes não tem sentido. Isso também ocorre quando uma norma caracteriza a ação mediante propriedades valorativas (abusivo, fraudulento, de má-fé) como ocorre no caso dos chamados conceitos jurídicos indeterminados, a que antes fizemos referência; e, também, quando as normas se recusam a configurar o caso e se limitam a estabelecer a obrigatoriedade prima facie de determinados princípios, a prevalência de cada um deles a respeito dos outros, somente pode ser estabelecida, atendendo ao peso das razões que cada um deles incorpora; ou quando as normas limitam-se a ordenar aos poderes públicos que persigam determinados objetivos coletivos (o pleno emprego, o acesso universal à habitação e a estabilidade econômica) sem pronunciar-se sobre os cursos de ações para consegui-los ${ }^{6}$.

De acordo com a concepção de Raz, as normas jurídicas regulativas deveriam constituir, todas elas, razões executivas ou peremptórias, isto é, suscetíveis de serem aplicadas sem necessidade de deliberação por parte de seus destinatários, porque apenas assim se preserva a vantagem de

\footnotetext{
6 Inclusive no caso de regras com autonomia semântica cabe dizer que, se bem é possível estabelecer seu significado e alcance prescindindo de suas razões subjacentes, também se governam por elas convenções interpretativas mais complexas que ordenam atender, na hora de estabelecer tais significados e alcance, as razões subjacentes às mesmas. Refirome ao tipo de convenções interpretativas referidas, por exemplo, nos artigos 3 e 4 do Código Civil espanhol, quando dizem que, na interpretação das normas, deve-se atender "fundamentalmente ao espírito e finalidade" delas ou quando prescrevem a aplicação analógica das normas "quando estas não contemplam um suposto específico, mas regulam outro semelhante entre os que têm razão idêntica".
} 
contar com autoridades, nos termos já vistos, que nos economizam dos custos da deliberação. Mas a imagem, evidentemente, implica o empobrecimento injustificado da diversidade de normas jurídicas regulamentadoras e da diversidade de forma em que cada uma delas pretende incidir na razão prática de seus destinatários. Muitas delas, como temos visto, não é o caso de que não possibilitam fundamentar a adoção de cursos de ação, prescindindo da deliberação, senão que, apenas podem incidir no nosso raciocínio prático de forma precisamente deliberativa.

Certamente Raz tem consciência de que nossas práticas jurídicas são muito mais complexas do que a mera aplicação das razões executivas ou peremptórias e, para encarar essa dificuldade, distingue entre o "raciocínio para estabelecer o conteúdo do direito" - no qual não caberiam avaliações e se governaria com puros argumentos de fato - e o "raciocínio com base no direito" que deveria integrar o dado, registrado pelo "raciocínio para estabelecer o conteúdo do direito" de que ele concede discricionariedade aos juízes para afastar-se do ordenamento pelo próprio direito, sempre que haja razões morais importantes para fazê-lo" (RAZ, 2001, p. 207). Mas esta última consideração é, na minha opinião, de consequências devastadoras para a construção de Raz: porque, se assim fosse, resultaria que aquilo que a seu juízo constitui a vantagem de possuir um sistema jurídico (diminuir os custos de deliberação) acabaria por completo na hora da aplicação judicial dele. Sendo assim, as coisas para a aplicação judicial, não se vê como os particulares poderiam preservar para si mesmos essa vantagem. E, por outro lado, a reconstrução do raciocínio judicial embasado na distinção afasta ainda mais Raz do que são as crenças compartilhadas entre os juristas, porque estes discutem a eventual justificação de deixar de lado, em certo caso, uma regra aplicável ao mesmo, não como se fora um problema de justificação moral no exercício de um poder discricionário, mas um problema de justificação jurídica, isto é, de justificação derivada de razões jurídicas, cujo peso superior move a regra como fundamento da decisão. 


\section{Uma Visão Alternativa}

Assim, pois, tanto em Raz como em Alchourrón e Bulygin nos encontramos com uma desconfiguração por empobrecimento do que se deve levar em conta quando chega o momento de estabelecer o conteúdo do Direito. Em Alchourrón e Bulygin, apenas leva-se em conta o conteúdo de um só tipo de enunciado (e suas consequências lógicas): aquele que correlaciona um caso com uma solução normativa, aos que hoje é comum chamar de regras e para os que Alchourrón e Bulygin reservam o uso do termo "norma". Em Raz, apenas conta o conteúdo das "instruções executivas" das autoridades, cuja identificação pode levar-se a cabo e seu significado pode ser estabelecido mediante puros argumentos de fatos, sem introduzir elementos avaliativos de qualquer espécie.

Essas duas operações de redução encontram-se assemelhadas da seguinte maneira: apenas as regras, isto é, os enunciados que correlacionam casos com soluções normativas (apenas enunciados que tenham essa estrutura) podem operar como razões executivas ou peremptórias (podem incidir dessa maneira no raciocínio prático de seus destinatários). Ter essas estruturas é condição necessária para que elas possam operar de tal maneira (prescindindo da deliberação) como guias de ação. Certamente, para completar as condições suficientes, é preciso que esses enunciados cumpram uma condição adicional: que as propriedades que configuram o caso e a ação ordenada apareçam caracterizados descritivamente (porque a presença de predicados valorativos implica a necessidade de deliberação acerca de suas condições de aplicação). Mas convém insistir que se trata, em todo o caso, meramente de condições suficientes de uma possibilidade: isto é, uma regra em que a propriedade do caso e a ação ordenada apareçam caracterizadas descritivamente pode operar o raciocínio prático de seus destinatários da maneira que, para Raz, constitui a única forma adequada na hora de estabelecer o conteúdo de Direito, isto é, de maneira completamente opaca, ou cega, a suas razões subjacentes. Mas pode fazê-lo também de maneira mais sensível a essas razões, de forma que tais razões (o "espírito e finalidade" das normas a que alude o Código Civil espanhol) sejam levadas em conta na hora de determinar o exigido pela regra (ampliando ou restringindo, por exemplo, seu significado lite- 
ral). Que as convenções interpretativas vigentes em nossas comunidades jurídicas se orientam melhor por essa última direção não é algo que requeira, creio eu, argumentação especial.

É essa redução das normas jurídicas regulativas a enunciados de um tipo apenas (no caso de Alchurrón e Bulygin) que estabelece o conteúdo do direito ao serem assumidos como razões executivas (no caso de Raz), o que, na minha opinião, está na raiz da falta de adequação de ambas as teorias, por um lado, e de forma imediata às crenças compartilhadas pelos juristas, e por outro e imediatamente, à realidade do direito (que se faz operacional como realidade institucional através do jogo de crenças compartilhadas).

Em Political Liberalism, escreve Rawls, caracterizando sua própria concepção de filosofia política, que "o que fazemos é agrupar essas convicções decantadas [...] [na cultura política de uma sociedade democrática] e tratar de organizar as ideias e os princípios básicos implícitos até convertê-los em uma concepção política coerente da justiça" (RAWLS, 1993, p. 98). Parafraseando Rawls - e frente ao que representam concepções como a de Alchourrón e Bulygin e a de Raz - eu diria que uma boa Teoria do Direito é a que proporciona uma imagem que seja capaz de organizar um todo coerente de ideias fundamentais divididas na cultura jurídica pública de nossas comunidades jurídicas. Nos últimos anos venho tentando trabalhar nessa direção em companhia de Manuel Atienza. O que segue - com relação aos problemas das lacunas do Direito - é, por isso mesmo, fortemente dependente (e, de certo modo, uma mera explicitação) da teoria dos enunciados jurídicos que esboçamos ambos em Las piezas Del derecho e na aplicação dessa teoria às figuras do abuso de Direito, a fraude da lei e o desvio de poder que mostramos em Ilícitos atípicos ${ }^{7}$.

Mas antes de abordar o tratamento das lacunas de forma que resulte coerente com a Teoria do Direito que temos elaborado, Atienza e eu mesmo, é preciso contornar um par de obstáculos preliminares: o primeiro deles é o do status normativo das ações não reguladas, o segundo, inti-

Atienza; Manero, op. cit. 1996. 
mamente vinculado com o anterior, é o da simetria (ou falta de simetria) entre as justificações correspondentes às decisões judiciais de aceitar ou de recusar a demanda.

Falar de status normativo das ações não reguladas parece, de início, algo assim como uma violação dos limites da linguagem normativa, conforme Carrio (2001). As ações não reguladas são precisamente isso, ações não reguladas e, por isso, carentes de status normativo. Agora, o que implica dizer de uma ação que carece de status normativo com relação a certo sistema de normas? Quer dizer que essa ação não se vê afetada por nenhuma norma desse sistema. Ou, dito de outra forma, que - igual ao que ocorre com a permissão expressa - nenhuma norma desse sistema é violada pelo sujeito que tanto realiza a ação como se abstém de realizá-la. Nesse sentido, a disponibilidade da ação para o sujeito, em relação a esse sistema de normas, é a mesma tanto se a ação não está regulamentada pelo sistema como se a ação esta permitida pelo sistema. O sistema não impõe restrição alguma sobre a conduta em nenhum dos dois casos, de acordo com o pensamento de Hierro (2002). E essa é a razão segundo a qual as condições de justificação da aceitação ou da negação do Direito da demanda não são simétricas: para a aceitação da demanda, essa necessita de uma relação com a conduta do demandado sem aplicabilidade de norma e que o demandado a tenha violado; para a negação da demanda, não é preciso que a conduta do demandado constitua um caso de complemento (se a norma em questão é de mandato) ou de uso ( se a norma em questão é permissiva) de uma norma. É também suficiente que se trate de uma conduta não sujeita a norma.

Isso parece-me óbvio! Mas não há dúvida de que, a partir daqui, surgem com naturalidade diversas objeções. Falarei apenas de duas. A primeira objeção seria a seguinte: se a ausência de regulamentação de uma ação produz os mesmo efeitos para o sujeito da ação que a regulamentação da mesma por meio de uma regra permissiva, por que razão o legislador faz regras permissivas? Em Las piezas Del Derecho, colocamo-nos Atienza e eu a questão e mostramos como o ditado da regra permissiva pode cumprir, dados os contextos apropriados, diversas funções importantes: 1) cancelar uma proibição, em tal caso, o dito de uma regra permissiva equivale a uma disposição derrogatória; 2) excetuar 
uma proibição. Em tal caso, o enunciado da regra permissiva equivale ao enunciado de uma disposição que excepcionara a proibição de que se trata; 3) esclarecer que um dado caso não está compreendido no alcance de uma proibição. Nesse caso, o dito da regra permissiva equivale ao dito de uma disposição definidora da conduta coberta pela regra permissiva; 4) introduzir indiretamente uma proibição (de proibir, de impedir ou de sancionar) às autoridades subordinadas. Nesse caso, o dizer da regra permissiva equivale ao dizer de uma regra proibitiva (de proibir, impedir ou sancionar) as autoridades subordinadas. De maneira que a relevância das regras permissivas parece poder explicar-se inteiramente em termos de regras proibitivas, de derrogação ou exceção das mesmas e de definições. Assim, por este lado, não parece haver dificuldade para a tese e que, a ausência de regulação (de proibição) e, a permissão, são situações equivalentes para o sujeito.

A segunda objeção óbvia que suscita a tese anterior é a seguinte: alguns sistemas (ou subsistemas) jurídicos contêm regras de clausura permissivas (que permitem expressamente tudo o que não proíbem outras regras do sistema), enquanto outros sistemas (ou subsistemas) não contêm tais regras de clausura. Nos nossos sistemas jurídicos, a primeira situação dá-se de maneira muito central no Direito Penal e também eventualmente em outros setores como o Direito Administrativo sancionador, - a ausência de regras de clausura permissivas - é a situação normal em todo o âmbito do Direito Privado. E, indubitavelmente, a presença de tais regras de clausura permissivas marca uma diferença importante entre o direito penal, segundo o qual, se uma conduta não está expressamente proibida na regra então está, sob o ponto de vista do Direito Penal, permitida sem necessidade de deliberação ou ponderação alguma, enquanto que, no Direito Civil, por exemplo, a ausência de proibição expressa por uma regra não garante que a conduta em questão não resulta estar ao final proibida, depois de uma ponderação que inclua todas as razões relevantes. Mas o mesmo ocorre, nos mesmos setores do Direito, com condutas expressamente permitidas por uma regra: também aqui a permissão pode deslocar-se em favor da proibição após uma ponderação que inclua todas as razões relevantes (e há figuras jurídicas estabelecidas precisamente para operar dito deslocamento, como é o caso do abuso de direito, da fraude 
da lei e do desvio de poder). Diríamos, então, que a diferença importante entre o Direito Penal e outros setores do Direito não se encontra no sentido de que o primeiro permita em sentido forte (pela presença nele de uma regra de clausura permissiva) o que em outros setores se permite apenas em sentido fraco (pela mera ausência de uma regra proibitiva), senão que o primeiro é, como sistema de proibições, um sistema exclusivo de regras, enquanto que, em outros setores, a ausência de regras ou a presença de regras permissivas pode ver-se deslocada, num juízo final sobre a conduta de que se trate um dado caso, por considerações de princípios. Dito de outra forma, embora o sistema de proibições penais seja um sistema de regras fechado, o sistema de proibições de outros setores do Direito é um sistema de regras aberto às exigências derivadas dos princípios, isto é, das razões subjacentes às regras. Ou, dito de outra forma, no Direito Penal não cabe a distinção - que cabe em outros setores do Direito - entre os juízos de proibição em virtude de regras e de juízos de proibição considerando todos os fatores relevantes, mais do que no sentido de excepcionar, no juízo final, proibições contidas em regras pré-estabelecidas, mas não no sentido de transformar em juízos finais de proibição o que aparece permitido por tais regras.

O que tudo isto implica é que a relação entre as regras do Direito Penal e suas razões subjacentes opera de maneira distinta ao modo como opera a relação entre as regras de outros setores do Direito e suas razões subjacentes. No Direito Penal o papel das razões subjacentes para delimitar o âmbito do penalmente ilícito se encontra limitado no seguinte sentido: uma vez estabelecidas as regras pelo legislador, apenas cabe apelar, por parte dos órgãos aplicadores, às razões subjacentes às mesmas para excepcionar proibições. Mas não para ampliar o âmbito do penalmente ilícito. Nesse sentido, o sistema de regras do Direito Penal é um sistema fechado (vale a pena insistir - na direção da ampliação de proibições, não na direção de excepcioná-las). Pelo contrário, nos outros âmbitos do Direito, o sistema é um sistema aberto à revisão de suas regras e à luz de suas razões subjacentes tanto na direção de ampliar como na de restringir as proibições contidas naquela.

Naturalmente, falar de relações entre as regras e suas razões subjacentes implica situar-se numa concepção de Direito que - como a que 
temos tratado de elaborar Atienza e eu mesmo nos últimos anos - vai mais além dos limites de concepções do Direito como as de Alchourrón e Bulygin e de Raz. Vai mais além dos limites em um duplo sentido. Em primeiro lugar, que vai mais além de Alchourrón e Bulygin no sentido de dar conta da presença no Direito de normas jurídicas entre um caso genérico - entendido como um conjunto de propriedades - e uma solução normativa, entendida como qualificação deóntica conclusiva de uma dada ação. Em segundo lugar, que vai além de Raz, no sentido de dar conta da presença no Direito de normas regulativas que não pretendem operar no raciocínio de seus destinatários, não como razões ("protegidas" ou "executivas") destinadas a substituir a deliberação, mas como integrante do processo deliberativo.

Esse duplo "ir mais além” resulta, basicamente, em uma imagem da dimensão regulativa do Direito como uma estrutura de dois níveis: as regras e os princípios que as justificam (e que constituem as razões subjacentes daquelas ). Os princípios têm, de um lado, uma estrutura distinta daquela que Alchurrón e Bulygin apresentam como sendo comum a todas as regras; por outro lado, e precisamente em virtude dessa estrutura distinta, não podem pretender operar no raciocínio prático como razões "executivas" ou "protegidas". Vejamos rapidamente tudo isso. O característico dos princípios se encontra, pelo lado do antecedente, em que este não contém outra coisa senão a propriedade de que exista uma oportunidade de realizar a conduta prescrita no consequente (trata-se, pois, de normas categóricas no sentido de von Wright), e pelo lado do consequente, em que este não contém um dever conclusivo, mas meramente prima facie de realizar uma dada conduta. Tal dever prima facie transforma-se em dever conclusivo sempre que, em relação com as propriedades do caso, não concorra com outro princípio que tenha, em relação com estas mesmas propriedades, um maior peso. O resultado dessa ponderação entre princípios concorrentes é uma regra que estabelece a prevalência de um deles, dadas certas circunstâncias genéricas, isto é, o dever conclusivo de realizar, dadas tais circunstâncias, a conduta prescrita no consequente de um deles. É precisamente por essas características estruturais que os princípios não podem pretender excluir a deliberação de seus destinatários como base da determinação de sua conduta a seguir, pois a determinação de quais 
são os deveres conclusivos em um certo caso não pode realizar-se, caso se raciocine a partir de princípios, mais do que mediante um processo deliberativo que estabeleça a prevalência de algum deles em relação às propriedades do caso. Essa determinação dos deveres conclusivos, dadas certas combinações de circunstâncias genéricas é, normalmente, tarefa do legislador. Mas como Hart (1968) enfatiza, o legislador não é onisciente e não é, por isso, capaz de antecipar todas as combinações de circunstâncias genéricas que possam apresentar-se nos casos individuais futuros. É por isso que as regras - para dizê-lo na terminologia que Schauer (2002) tem posto ultimamente em moda - são sempre potencialmente supraincludentes ou infraincludentes em relação com as ponderações entre princípios que estão subjacentes: é sempre possível que os casos individuais apresentem propriedades genéricas adicionais às previstas nas regras que se aplicam e que estas propriedades gerais demandem o deslocamento da ponderação entre princípios contidos na regras aplicável em benefício de um novo sopesamento (que se expressa numa nova regra); e é assim sempre que ocorram casos que apresentam combinações de propriedades distintas às previstas nas regras, e que o equilíbrio entre princípios ofereça o mesmo resultado que aquele que oferece em relação com as combinações de propriedades previstas nas regras. Para enfrentar ambos os tipos de situações, nossos sistemas jurídicos e nossas práticas argumentativas contêm instituições e modos de raciocínio bem conhecidos. Para o primeiro tipo de situação quando as regras preestabelecidas resultam supraincludentes, isto é, quando enfrentamos casos nos quais a relação deles com as regras aplicáveis em virtude de seus termos nos parecem sujeitas a exceções implícitas em relação com os princípios que as justificam, os sistemas de commom law dispõem da técnica de distinguishing e os de base continental tem desenvolvido, entre outros recursos, categorias como o abuso de direito, a fraude da lei e o desvio de poder. Para enfrentar o segundo tipo de situação - quando as regras preestabelecidas resultam infraincludentes ou quando não dispomos de regras preestabelecidas que expressem a ponderação entre princípios relevantes - dispomos das diversas modalidades de raciocínio analógico. Ocorre analogia legis quando certa regra resulta infraincludente em relação com as exigências dos princípios que constituem sua justificação subjacente; há a analogia 
iuris quando o equilíbrio entre os princípios relevantes exige a geração de uma nova regra, ainda não existindo uma regra prévia que consideremos como infraincludente.

É no marco dessa concepção da dimensão regulamentadora do Direito como uma estrutura de dois níveis - as regras e suas razões subjacentes, isto é, os princípios que as justificam - onde se pode elaborar, a meu juízo, uma teoria das lacunas que resulte coerente com as ideias compartilhadas pelos juristas e encare aquelas situações que realmente se discutem, em nossa prática jurídica, sob esse rótulo.

As lacunas, desde essa concepção, aparecem como déficits dos tipos do sistema de regras preestabelecidas em relação às exigências derivadas dos princípios que as justificam. Pois o sistema de regras, pelo que agora nos interessa, pode ser deficitário em relação às exigências derivadas dos princípios, de duas maneiras distintas: pode, em primeiro lugar, carecer, em relação com o caso, de regra na qual subsumi-lo, de tal forma que a presença de tal regra vem exigida pelo sopesamento entre os princípios relevantes; pode, em segundo lugar, não se considerar como relevante uma propriedade que, de acordo com as exigências derivadas do equilíbrio, deveria ser considerada relevante. Obtemos assim os conceitos de lacuna normativa e de lacuna axiológica que, como vamos ver imediatamente, não são mais que reelaborações dos conceitos correspondentes de Alchourrón e Bulygin, que se diferenciam destes unicamente nos dois extremos seguintes: primeiro, em que integram a consideração, a qual venho fazendo repetidas referências, da dimensão regulativa do Direito como composta de dois níveis; e segundo, em que integram assim mesmo a consideração antes exposta de que a regulamentação equivale pragmaticamente à regulamentação permissiva. Os dois conceitos seriam os seguintes:

Determinado caso constitui uma lacuna normativa de certo sistema jurídico se e somente se (1) esse sistema jurídico não contém uma regra que correlacione o caso com uma solução normativa e (2) o equilíbrio entre os princípios relevantes a esse sistema jurídico exige uma regra que correlacione o caso com uma solução normativa que qualifique a conduta de que se trate como obrigatória ou proibida. 
Certo caso constitui uma lacuna axiológica de um determinado sistema jurídico se e somente se (1) esse sistema contém uma regra que soluciona o caso, mas (2) sem que tal regra considere como relevante uma propriedade que, de acordo com as exigências que se derivam do equilíbrio entre os princípios relevantes desse sistema jurídico, dever-se-ia considerar como relevante.

Alguns comentários a propósito dessas definições. A definição de lacuna normativa exclui de seu âmbito aqueles casos não cobertos por uma regra em relação com os quais o equilíbrio dos princípios relevantes do sistema determinaria que ela permitisse, tanto a realização, como a omissão da conduta de que se trate. De acordo com a definição, pois, em relação com o caso das férias matrimoniais o sistema não conteria lacuna alguma. A razão é que, de acordo com os princípios informativos da instituição matrimonial nos sistemas jurídicos que reconhecem a igualdade entre os sexos, uma eventual regra referente a esse caso não poderia ser nada mais que permissiva: permitiria a cada um dos cônjuges, tanto acomodar como não acomodar, a sua conduta à conduta do outro cônjuge de passar as férias juntos em um determinado lugar. E esse mesmo efeito - o fato de que aderir, ou não aderir, aos desejos do outro cônjuge sua conduta disponível, é dizer, livre de restrições normativas, para ambos - vem determinado igualmente pela ausência de regra a respeito. Cada um dos cônjuges se encontra, a respeito do outro, numa situação de privilégio e não de não-direito: cada um deles não tem direito a exigir do outro que o acompanhe a um determinado lugar de férias e cada um dos dois tem, assim também, o privilegio de não atender o desejo de férias do outro.

Por outro lado, é óbvio no exemplo, que cada um dos cônjuges tem o interesse que o outro o acompanhe ao lugar de férias escolhido por ele (ou ela). $\mathrm{O}$ marido tem um interesse de que a esposa o acompanhe à França e a esposa tem o interesse que o marido a acompanhe à África do Sul. Há, então, um genuíno conflito de interesses. E um conflito de interesses que o Direito não soluciona. Não há a meu juízo lacuna alguma ${ }^{8}$. Os con-

8 Concordo, pois, absolutamente com Fernando Atria (supra p.17, n.7) que não basta a existência de um conflito de interesses não resolvido pelo sistema jurídico para poder falar em lacuna. Mas não concordo que, no texto da mesma nota, argumente que se 
flitos de interesses não resolvidos pelo sistema jurídico que não supõem lacunas por parte desta são, a meu juízo, muito numerosos e de grande importância em muitos setores do Direito Privado, como por exemplo, no Direito dos Contratos. É claro que na negociação, por exemplo, de um contrato de compra e venda, o potencial comprador tem um interesse em fixar um determinado preço e o potencial vendedor tem o interesse de fixar o preço mais alto. Há, aqui, então, um claro conflito de interesse. E um conflito de interesses que o Direito, claramente, não resolve: porque cada uma das partes tem o privilegio de não aceitar o preço proposto pela outra parte e, por sua vez, não tem o direito de exigir da outra parte que aceite o preço que ele propõe. $\mathrm{O}$ sistema jurídico poderia, desde logo, resolver semelhantes conflitos de interesse configurando a relação correspondente (entre comprador e vendedor e entre cônjuges) como uma relação de potestade/sujeição, isto é, situando a uma das partes em posição dominante. Mas isso é precisamente o que um sistema jurídico liberal (a respeito dos contratos e das relações matrimoniais) não pode fazer sem deixar de ser tal. Um sistema liberal caracteriza-se, pois, necessariamente, por deixar sem resolver um bom número de conflitos de interesses.

Quanto às lacunas axiológicas, acredito que a principal vantagem do conceito, tal como aqui foi trazido, é que permitem dar conta do problema das chamadas exceções implícitas sem as consequências indesejáveis de outras reconstruções alternativas. No modelo clássico de Alchourrón e Bulygin - no qual a dimensão regulamentadora do Direito aparece reduzida ao formato de regras - quem assinala a existência de uma lacuna axiológica está formulando uma crítica necessariamente externa ao sistema jurídico: uma crítica formulada de uma hipótese de relevância distinta da tese de relevância que o sistema assegura e o órgão jurisdicional que resolva o caso fundamentando tal solução numa regra configurada de

afirmo (em Ruiz Manero, Jurisdicción y normas) minha concordância com Alchourrón e Bulygin em que as lacunas são conflitos de interesse não resolvidos pelo sistema jurídico, deve-se, por razões de coerência, afirmar-se que, cada vez que existe um conflito de interesses não resolvido pelo sistema, ele contém uma lacuna. A resposta a essa objeção de Fernando Atria é muito singela: as lacunas são, com efeito, conflitos de interesses não resolvidos pelo sistema jurídico, mas nem todos os conflitos de interesses não resolvidos pelo sistema jurídico constituem lacunas. 
acordo com qualquer hipótese de relevância distinta da tese de relevância contida numa regra do sistema, resolve necessariamente o caso de maneira não fundamentada juridicamente: o ato de fundamentar as soluções no Direito implica, dessa forma, pagar o preço de que certo número de tais decisões apareçam como valorativamente incoerentes. Fidelidade ao Direito e coerência valorativa das decisões jurídicas aparecem, assim, como termos de uma discussão excludente em relação com os supostos de lacuna axiológica. No modelo de Raz, o problema se resolve de acordo com a tese de que o Direito confere aos juizes discricionariedade para afastar-se sempre que haja razões morais fortes para fazê-lo. De certo modo, a concepção de Raz acaba admitindo que o Direito não pretende ter autoridade sobre os juizes. Mas, como se tem argumentado convincentemente, no dizer de Bayon (2002), se o Direito não pretende exercer autoridade sobre seus próprios órgãos de aplicação, não se vê como possa pretender ter autoridade em absoluto.

No marco da concepção aqui esboçada, pelo contrário, não há dificuldade para dar conta de como, quando os tribunais deixam de lado - como fundamento de sua decisão - uma regra jurídica aplicável em virtude de seus termos ao caso de que se trate, podem estar fazendo-o por razões jurídicas, e ditando assim a solução exigida pelo Direito. Sem deixar de reconhecer a pretensão de autoridade do Direito sobre seus órgãos de aplicação, a fidelidade ao Direito e a coerência valorativa das decisões jurídicas se reconciliam.

Para terminar: a visão alternativa que aqui é traçada termina propondo alguns conceitos de lacuna normativa e de lacuna axiológica que não são nada mais que adaptações (ou reformulações) dos conceitos correspondentes encontrados em Normative Systems. Algum leitor caritativo poderia assinalar que esta visão não mostra outra coisa senão minha incapacidade para o pensamento original. Sem negar a parte de razão disto, acredito que, vale a pena por a devida ênfase sobre algo mais importante que também é indicativo deste "acabar propondo uma mera reformulação de conceitos já presentes em Normative Systems": a saber, a potência e a fecundidade - ainda no marco de uma concepção distinta do Direito - dos instrumentos conceituais que Carlos Alchourrón e Eugenio Bulygin nos presentearam há mais de 30 anos. 


\section{Referências}

ALCHOURRÓN, Carlos; BULYGIN, Eugenio. Normative Systems. Viena: Springer, 1971.

. La concepción expresiva de las normas. In: ALCHOURRÓN, Carlos; BULYGIN, Eugenio. Análisis lógico y Derecho. Madrid: Prisma, 1991. p. 121-153.

. Los límites de la lógica y el razonamiento jurídico. In: ALCHOURRÓN, Carlos; BULYGIN, Eugenio. Análisis lógico y Derecho. Madrid: Prisma, 1991. p 305.

ATIENZA, Manuel e MANERO, Ruiz. Ilícitos atípicos. Sobre El abuso Del derecho, El fraude de ley y La desviación de poder. 1996.

. Las piezas Del derecho. Teoria de los enunciados jurídicos. Barcelona: Ariel, 1996. . Jurisdicción y normas. Madrid: Centro de Estudios Constitucionales, 1990.

ATRIA, Fernando. Lagunas en el Derecho. Uma controversia sobre el Derecho y la función judicial. Madrid- Barcelona: Marcial Pons, 2005. BAYÓN, Juan Carlos. Derecho, convencionalismo y controvérsia. In: NAVARRO, Pablo E; REDONDO, Maria Cristina (comp). La relevancia del derecho: ensayos de filosofia jurídica, moral y política. Barcelona: Gedisa, 2002, p. 70.

BULYGIN, Eugenio. Enunciados jurídicos y positivismo: respuesta a RAZ. (1981) In: ALCHOURRÓN, Carlos; BULYGIN, Eugenio. Análisis lógico y Derecho. Madrid: Prisma, 1991, p. 427-438.

CARRIO, G. Sobre los limites da lenguage normativo. Buenos Aires: Astrea, 2001.

DWORKIN, Ronald M. The Model of Rules. Chicago: The University of Chicago Law Review, v. 35, n. 1 (1967), p. 14-46.

HARE, R. M. El linguage de la moral. México: UNAM, 1975 (1952). 
HART. H. L.A. El concepto de derecho. 2. ed. Buenos Aires : AbeledoPerrot, 1968.

HIERRO. El concepto de justicia y la teoría de los derechos, en Díaz y Colomer (Eds.) 2002.

RAZ, Joseph . La Autoridad del Derecho. Ensayos sobre el Derecho y la Moral. UNAM, México, 1982. 1972.

. Legal principles and the limits of law. Yale Law Journal, 1971. La ética en el ámbito público - Ensayos sobre la moralidad del derecho. - Gedisa Editorial - 2001.

. Razón práctica y normas. Madrid: Centro de Estudios Constitucionales; 1991.

. Postema on Law's Autonomy and Public Practical Reason: a Critical Comment.Cambridge: Legal Theory, v. 4, n. 4, 1998, p. 1-20. RAWLS, John. O Liberalismo Político. 2. ed. São Paulo: Editora Ática, 2000.

SCHAUER, Frederick. Playing by the Rules: a philosophical examination of rule-based decision-making in law and life. Oxford: Clarendon, 2002. 